\title{
Beam-Induced Reaction between meta- Nitrobenzyl Alcohol and Dipyridocyanine Dyes in Liquid-Secondary-Ion Mass Spectrometry
}

\author{
Sharon W. Lemire, Xiaodong Zhao, Laren M. Tolbcrt, and \\ Kenneth L. Busch \\ School of Chemistry and Biochemistry, Georgia Institute of Technology, Atlanta, Georgia, USA.
}

\begin{abstract}
Analyses of cationic dipyridocyanine dyes by liquid-secondary-ion mass spectrometry in a liquid matrix of meta-nitrobenzyl alcohol (mNBA) provide evidence for beam-induced addition reactions between the sample molecule (C) and the mNBA solvent. The ionic products of these addition reactions formally correspond to $\left[\mathrm{C}+\mathrm{mNBA}-\mathrm{O}_{2}\right]^{+},[\mathrm{C}+$ mNBA $-\mathrm{O}_{2}-\mathrm{H}^{+}$; and $\left[\mathrm{C}+\mathrm{mNBA}-\mathrm{O}_{2}-2 \mathrm{H}\right]^{\prime}$. Initial loss of $\mathrm{H}$ from the adduct ion extends the conjugation of the adduct into the mNBA ring structure, whereas the final loss of hydrogen is thought to be promulgated by the formation of a benzylic radical stabilized through resonance with the $\pi$-electron system of the nitrobenzyl alcohol. Alternatively, two hydrogens may be lost from the alcohol functionality to form an aldehyde. (/ Am Soc Mass Spectrom 1994, 5, 1017-1020)
\end{abstract}

$\mathrm{B}$ eam-induced reactions between sample molecules, between the sample molecule and the solvent matrix [1-5], and extensive and varied reactions in the bombarded solvent itself [6-9] have been well documented in fast-atom bombardment (FAB) and liquid-secondary-ion mass spectrometry (LSIMS). Many reactions between the solvent and the sample molecules generally can be classified as acid-base reactions, intermolecular alkyl transfers, addition-substitution reactions, such as the simple additions of solvent to the sample to form $[\mathrm{MH}+$ solvent $\left._{n}\right]^{+}$ligand exchange reactions, or oxidationreduction reactions [10]. Much work has been devoted to the documentation of oxidation-reduction reactions, in particular. A correlation has been drawn in several instances (primarily organic dyes) between the susceptibility of the sample molecule to reduction processes (formulated as addition of hydrogen atoms to the molecule) in FAB or LSIMS mass spectrometry, and the redox potential as established through independent experiments [11]. In studies with other sample classes (porphyrins, quaternary ammonium compounds), no rigorous correlation has been uncovered [12].

For the formation of ions that correspond to simple addition products between solvent molecules (S) and sample molecules (M), simple noncovalent interactions such as hydrogen bonding are thought to hold the

Address reprint requests to Professor Kenneth L. Busch, School of Chemistry and Biochemistry, Georgia Institute of Technology, Atlanta, Ga 30332-0400. adduct together. Although as many as five solvent molecules can be bound to a single sample ion [13], no discrete structural features within the sample molecule have been identified that facilitate adduct formation. In some cases, product ion tandem mass spectrometry experiments further show that collision-induced dissociation does not force simple reversion of the complex to the ionized sample molecule and the neutral solvent molecule [13]. Little attention usually is paid to these addition products; they are simply identified as $\left[\mathrm{MH}+\text { solvent }_{n}\right]^{+}$and play only a straightforward role in confirmation of the molecular mass $M$. In this communication, we report an unusual addition reaction between a sample molecule and the solvent molecule that involves deoxygenation of the solvent. This adduct ion then undergoes further fragmentations to form resonance-stabilized product ions.

\section{Experimental}

Four dipyridocyanine dyes were synthesized [14] (Figure 1). Three molecular cations 1-3 contained iodide as the counterions; the fourth dye was comprised of cation 2 with tetraphenylborate as the anion.

Positive ion mass spectra of the cation and product ion tandem mass spectra of mass-selected adduct ions were acquired on a VG 70-SEQ hybrid mass spectrometer (VG Analytical Ltd., Manchester, UK) of EBqQ geometry. The primary ion beam was produced from a thermionic cesium ion source operated at $35 \mathrm{kV}$, which yielded a primary ion flux of approximately 10 


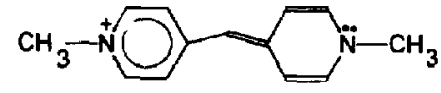

Cation 1

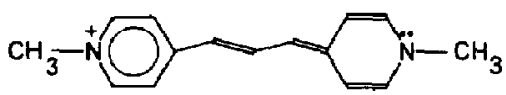

Cation 2

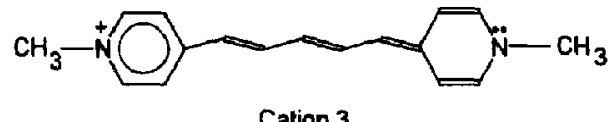

Cation 3

Figure 1. Structures of the cations 1-3 for the series of dipyridocyanine dyes studied by liquid-secondary-ion mass spectrometry.

$\mu \mathrm{A} / \mathrm{cm}^{2}$.Collision-induced dissociation at $60-\mathrm{eV}$ (laboratory frame) collision energy was used to fragment the adduct ion at $m / z \quad 320$. Ambient air was used as the collision gas at a pressure sufficient to attenuate the parent ion by $50 \%$. CsI was used to calibrate the mass scale of the instrument and mass resolution was determined at baseline as 1000. Exact mass measurements were carried out on a VG 705 instrument (VG Analytical) equipped with an Ion Tech (Middlesex, UK) source at a mass resolution of 8000 . meta-Nitrobenzyl alcohol (mNBA) was used as the solvent for LSIMS. meta-Nitrobenzyl alcohol, $m$ - aminobenzyl alcohol, and a second matrix, o-nitrophenyl octyl ether, were obtained from Aldrich Chemical Co. (Milwaukee, WI). Approximately $50 \mu \mathrm{g}$ of sample was added to $5 \mu \mathrm{L}$ of the matrix for each dye; 1-2 $\mu \mathrm{L}$ of the sample solution was placed on the stainless steel probe for each run.

\section{Results and Discussion}

The positive ion LSIMS mass spectrum (without background subtraction) of dipyridocyanine dye 1 is given in Figure 2. The molecule cation $\left(\mathrm{C}^{+}\right)$was observed as the base peak of $m / z 199$ (expected $199.1235 \mathrm{u}$; measured $199.1252 \mathrm{u}$ ). A less intense peak at $\mathrm{m} / \mathrm{z} 184$ corresponds to loss of a methyl radical from the intact cation, $\left[\mathrm{C}-\mathrm{CH}_{3}\right]^{+}$, and an ion at $m / z 185$ corresponds to an addition of hydrogen to the methyl-loss product ion or to direct loss of a methylene group from the cation. Sample-related ions at masses higher than that of $\mathrm{C}^{+}$are observed at $m / z 304,318,319$, and 320 . The spectrum was averaged over 10-scan increments during the run total of 30 scans. The insets in Figure 2, limited to the mass range of $280-330 \mathrm{u}$, show an increase in intensity over successive 10-scan increments for the adduct ions with respect to the intact cation, constant at $100 \%$ relative intensity. Other peaks in the mass spectrum can be attributed to the protonated solvent $[\mathrm{S}+\mathrm{H}]^{+}$, fragment ions from the sol-

\section{MASS SPECTRUM of the DIPYRIDOCYANINE CATION}

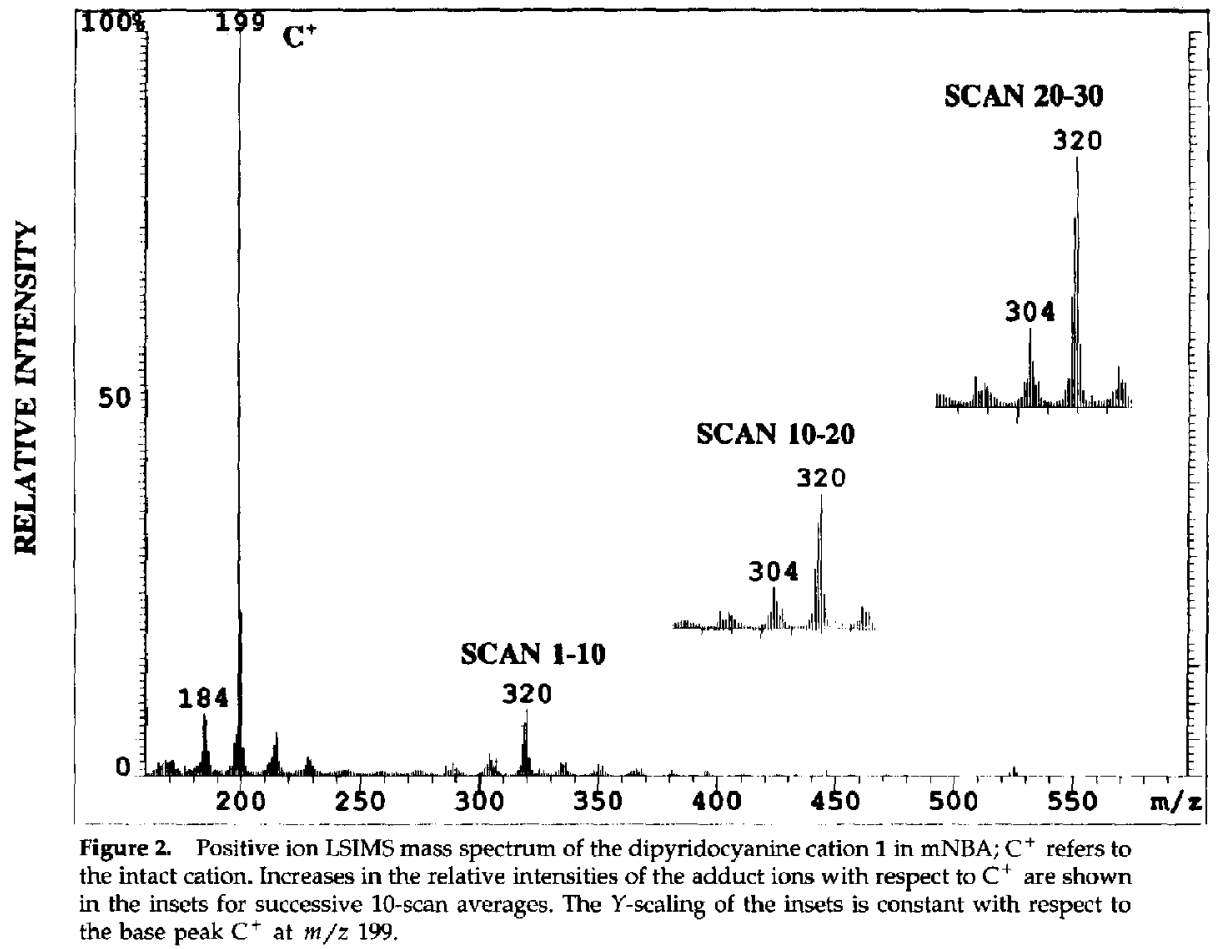


vent, or polymerization-product ions (or fragments therefrom) of mNBA.

The known empirical formula of cation 1 is $\mathrm{C}_{13} \mathrm{H}_{15} \mathrm{~N}_{2}$, the measured exact mass for the adduct suggests an ion empirical formula of $\mathrm{C}_{20} \mathrm{H}_{22} \mathrm{~N}_{3} \mathrm{O}$, so that the atoms added sum to $\mathrm{C}_{7} \mathrm{H}_{7} \mathrm{NO}$. This moiety is related to nitrobenzyl alcohol, itself $\mathrm{C}_{7} \mathrm{H}_{7} \mathrm{NO}_{3}$, through loss of $\mathrm{O}_{2}$. Adduct ion formation therefore corresponds to a deoxygenation reaction of the nitrobenzyl alcohol. The exact nature of the reactive species is unclear. Ions at $m / z 136$ and 137 in the mass spectrum of the $\mathrm{mINBA}$ solvent correspond to dissociations that involve the loss of at least one oxygen atom as $\mathrm{OH}$ or $\mathrm{H}_{2} \mathrm{O}$. There may be neutral analogs to these ions that are reactive with the sample cations and from which another loss of oxygen may occur. It also has been suggested that the nitro group in $\mathrm{mNBA}$ can be reduced to an amine (a deoxygenation) in a beam-induced reaction, and species derived from the amine rather than the original solvent molecule may be involved in the mechanism. Accordingly, a mass spectrum was acquired of cation 1 in glycerol with $m$-aminobenzyl alcohol (mABA) added. A low intensity ion at $\mathrm{m} / \mathrm{z}$ 320 was observed; however, the intensity of this ion does not increase over the course of the analysis. Instead, the ions at $m / z 199$ and 320 both decrease in intensity, whereas the ion at $m / z 124, \operatorname{lmABA}+\mathrm{H}]^{+}$, remains approximately the same. Therefore it does not appear that the reduced form of mNBA (mABA) adds to the sample molecule. The time dependence as well as the enhanced intensities of the adduct ions differentiate them from background signals at these same masses. To support the formation of the adduct ion as suggested, the mass spectra of dyes $\mathbf{1}$ and $\mathbf{2}$ also were recorded with an o-nitrophenyl octyl ether (NPOE) matrix. The mass spectrum of dye 1 contains the expected adduct ion at $\mathrm{m} / \mathrm{z} 418$ that corresponds to addition of NPOE to the sample molecule with loss of $\mathrm{O}_{2}$, and the mass spectrum of dye 2 in NPOE contains the analogous adduct ion at $m / z$ 444. Although the first steps of the reaction are unclear, they probably correspond to an electrophilic fragment $F$ (derived from solvent) attack on the electron-rich carbon indicated in Scheme I. Based on the exact mass measurement and the product ion spectrum, the ion at $\mathrm{m} / \mathrm{z}$ 320 may be drawn as shown in Structure 1 . The ion at $m / z 319$, represented by Structure 2 , is formed by loss of the amine hydrogen, which extends the resonance of the original dye molecule into the $\pi$-electron system of the dye and of the benzene ring of mNBA. Asterisks around one of the resonance forms of Structure 2 indicate the location of the odd electron within other resonance structures and show that it is possible to extend the original conjugation of the dipyridocyanine dye into the aromatic ring of the nitrobenzyl alcohol through expulsion of the amine hydrogen. Loss of a methyl group from Structure 2 would result in the ion at $m / z 304$. Loss of a $\mathrm{H}$ from $-\mathrm{CH}_{2} \mathrm{OH}$ leads to formation of a benzylic radical stabilized by resonance

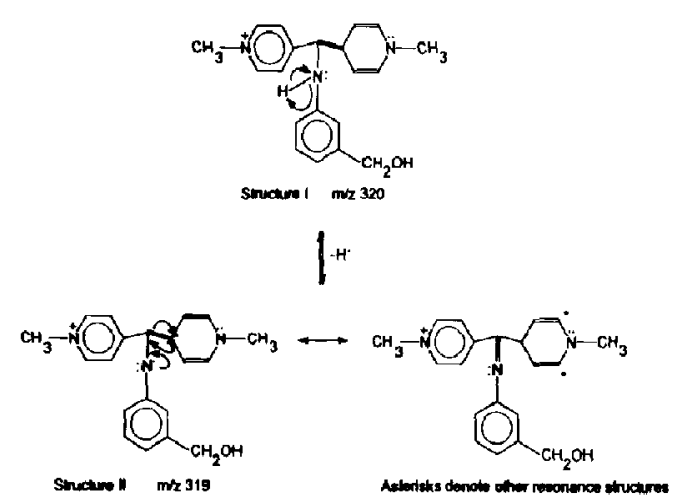

Scheme I. The proposed structure of the adduct ion produced from the reaction of the deoxygenated form of $\mathrm{mNBA}$ and the dipyridocyanine dye at $m / z 320$ is represented by Structure 1 . Structure 2 represents the radical cation at $m / z 319$ and one of the resonance structures contributing to stabilization of the product through extension of conjugation into the benzerte ring of mNBA. The asterisks in Structure 3 indicate equivalent locations of the odd electron within other resonance structures.

with the benzene ring, and forms the ion at $m / z 318$. Alternatively, two hydrogen atoms may be lost from $-\mathrm{CH}_{2} \mathrm{OH}$, which transforms the alcohol into an aldehyde group. Collision-induced dissociation of the mass-selected parent ion at $m / z 320$ produces product ions at $m / z 305$ and 290 , which corresponds to successive loss of the two methyl groups at either end of the dye molecule and confirms that these groups are retained within the adduct ion. A product ion at $\mathrm{m} / \mathrm{z}$ 198 is probably loss of $\mathrm{C}_{7} \mathrm{H}_{8} \mathrm{NO}$ (which represents the mNBA portion), and the product ion at $m / z 183$ is due to loss of a methyl group from the ion at $m / z 198$. Each of these results is consistent with the proposed structures as drawn.

Structures of the other dyes are formed by simple extension of the alkenyl chain of cation 1 by $(\mathrm{CH}=\mathrm{CH})_{n}$ where $n=1$ and 2 for cations 2 and 3 , respectively. Accordingly, with the $\mathrm{mNBA}$ matrix and for cation $2, \mathrm{C}^{+}$was observed at $m / z 225$, the ion $\left[\mathrm{C}-\mathrm{CH}_{3}\right]^{+\cdot}$ at $m / z 210$, and the adduct ions (as discussed) at $m / z \quad 346,345$, and 344. Loss of a methyl group from $m / z 345$ forms the ion at $m / z 330$. Similarly, for cation $3, \mathrm{C}^{+}$was observed at $m / z 251$, the ion $\left[\mathrm{C}-\mathrm{CH}_{3}\right]^{+1}$ at $m / z 236$, and the adduct ions at $m / z 372,371$, and 370 , respectively, with final loss of the methyl group also apparent.

The appearance of the adduct ions at the appropriate masses in the mass spectra of the homologous dipyridocyanine dyes supports the proposed structures. Because the time dependencies are similar in each case, we concluded that the adduct ions were the result of beam-induced reactions. The secondary-ion current intensity for the adduct ion for each of the cationic dyes increased over time, whereas intensities of mNBA and the sample decreased, a phenomenon considered to be indicative of a beam-induced reaction $[14,16]$. 


\section{Conclusions}

The adduct ions observed in the LSIMS mass spectra of these dipyridocyanine dyes are formed in an addition reaction that formally corresponds to deoxygenation of the solvent matrix molecule. As such, the reaction represents a type of reduction reaction initiated by the primary ion beam reported in only a few other instances [15-17]. A significant difference here is that the deoxygenation involves the matrix rather than the sample molecule. Expulsion of a single hydrogen atom from the adduct ion appears to be driven by the opportunity to extend the conjugated $\pi$-electron system of the proposed structure. Loss of a second single hydrogen atom to form the particularly stable benzylic radical would allow still further extension of the conjugated system as would the loss of two hydrogen atoms to form the aldehyde from the alcohol. The timedependent intensities of the $\mathrm{mNBA}$ ion and the adduct support the contention that this reaction is beam induced. L oss of $\mathrm{O}_{2}$ is supported by the results of the exact mass experiment and the proposed structure is further supported by the results of the collision-induced dissociation experiments.

\section{References}

1. Agnello, A.; DePauw, E.; Natalis, P. J. Am. Soc. Mass Spectrom. 1993, 4(4), 312-321.
2. Tuinman, A. A.; Cook, K. D. J. Am. Soc. Mass Spectrom. 1992, 3(4), 318-325.

3. Tuinman, A. A.; Cook, K. D. I. Am. Soc. Mass Spectrom. 1994, 5(2), 92-99.

4. Duffin, K. L.; Busch, K. L. Int. J. Mass Spectrom. Ion Processes 1986, 74, 141-152.

5. Brown, S. M.; Busch, K. L. Rapid Commun. Mass Spectrom. 1988, 2(11), 256-259.

6. Caldwell, K. A.; Gross, M. L. J. Am. Soc. Mass Spectrom. 1994, S(2), 72-91.

7. Keough, T; Ezra, F. S.; Russell, A. F.; Pryne, J. D. Org. Mass Spectrom. 1987, 22, 241.

8. Byrdy, F. A.; Busckı, K. L. Spectrosc. Lell. 1992, 25(6), 789-798.

9. Reynolds, J. D.; Cook, K. D.; Burn, J. L. E.; Woods, C. J. Am. Soc. Mass Spectrom. 1992, 3(2), 113-121.

10. Detter, L. D.; Hand, O. W.; Cooks, R. G.; Walton, R. A. Mass Spectrom. Rev. 1988, 7, 465-502.

11. Pelzer, G.; DePauw, E.; Dung, D. V; Marien, J. J. Phys. Chem. 1984, 88, 5065 .

12. Schurz, H. H,; Busch, K. L. Energy \& Fuels 1990, 4, 730-736.

13. Yin, J. Masters Thesis, Georgia Institute of Technology, Atlanta GA, 1993.

14. Tolbert, L. M.; Zhao, X. Synthetic Metals 1992, 57, 4782.

15. Santana-Marques, M. G. O.; Ferrer-Correia, A. J. V.; Gross, M. L. Anal. Chem. 1989, 61, 1442-1447.

16. Brown, R. M.; Creaser, C. S.; Wright, H. J. Org. Mass Spectrom. 1984, 19, 311-314.

17. Nakamura, T.; Nagaki, H.; Kinoshita, T. Bull. Chem. Soc. Jpn. $1985,58,2798-2800$. 